\title{
Endometrial stromal nodule: a rare entity presenting as fibroid polyp
}

\author{
Priyanka Baghotia $^{1 *}$, Monika Madaan ${ }^{1}$, Mukta Pujani $^{2}$, Neha Soni ${ }^{1}$
}

\author{
${ }^{1}$ Department of Obstetrics and Gynaecology, ESIC Manesar, Gurugram, Haryana, India \\ ${ }^{2}$ Department of Pathology, ESIC Faridabad, Haryana, India
}

Received: 25 September 2020

Accepted: 15 December 2020

\section{*Correspondence:}

Dr. Priyanka Baghotia,

E-mail: drpriyanka9120@gmail.com

Copyright: (c) the author(s), publisher and licensee Medip Academy. This is an open-access article distributed under the terms of the Creative Commons Attribution Non-Commercial License, which permits unrestricted non-commercial use, distribution, and reproduction in any medium, provided the original work is properly cited.

\begin{abstract}
Endometrial stromal sarcoma are rare malignant tumours of the uterus, mainly presenting in premenopausal women, make around $0.2 \%$ of all uterine malignancies. The annual incidence of ESS is 1-2 per million women. Diagnosis is usually made post operatively by pathological findings either in endometrial sample or in hysterectomy specimen done for some underlying pathology. Management is total hysterectomy with bilateral salpingo oophorectomy with hormone therapy in hormone sensitive cases. Ovaries can be preserved in young females with early-stage disease. We are presenting a case of endometrial stromal nodule in a 38 years old woman who presented to us with complaint of abnormal heavy uterine bleeding for one and half month.
\end{abstract}

Keywords: Pedunculated, Polypectomy, Immunohistochemistry

\section{INTRODUCTION}

Cancers arising from mesodermal structures like muscles and connective tissue are called sarcomas. Sarcomas of the uterus are uncommon, and may arise from connective tissue, smooth muscle or the endometrial stroma. ESS mainly affect younger women with mean age group 4258 years. Local recurrence and metastasis can occur even 20 years after diagnosis.

\section{CASE REPORT}

A 38-year-old woman presented in our gynecology outpatient department with complaints of heavy irregular menstrual bleeding for 1.5 months associated with pain lower abdomen. She is para 3, with all normal deliveries, last child birth 8 years back and tubal ligation done in post-partum period with no history of any other contraceptive use. She had normal regular menstrual cycles previously. Her general physical and systemic examination was normal except for mild pallor. On genital examination she had a pedunculated fibroid polyp of 4 by $3 \mathrm{~cm}$ with thick pedicle arising from uterus, uterus size was multiparous and adnexa was normal. So, decided for polypectomy and therapeutic curettage. All her routine hematological and biochemical investigations including chest X-ray and ECG were normal except for a $\mathrm{Hb}$ of. Ultrasound showed 3.9 by $3.08 \mathrm{~cm}$ endometrial polyp with $17.5 \mathrm{~mm}$ pedicle size with marked vascularity on doppler. CA-125 was $18.6 \mathrm{IU} / \mathrm{ml}$. After informed consent and preanesthetic clearance she was taken up for vaginal polypectomy and endometrial curettage in operation theatre. Polypectomy was done from base of pedicle which was high up near uterine fundus. As the OS was dilated due to polyp worm like projections of the adjacent myometrium could be felt near base of the polyp. Endometrial curettage was performed and samples saved in formalin and send for histopathological reporting. HPE showed tumour showing proliferation of endometrial stromal cells in fascicles and around blood vessels, cells showing round to oval nucleus with finely granular dispersed chromatin and inconspicuous nucleoli, with few hemorrhagic areas. Endometrial biopsy showed normal proliferating endometrium. Tumour cells on immunohistochemistry was CD10 and desmin positive, 
hence findings diagnostic for endometrial stromal sarcoma. Patient called back for further management and the need of surgery that is total abdominal hysterectomy with bilateral salpingo oophorectomy with lymph node dissection and requirement of post-operative hormonal therapy if needed, were explained. MRI abdomen and pelvis were done which showed no significant abnormality, minimal fluid in endometrial cavity with no obvious mass or thickening, no lymphadenopathy seen. The woman was taken up for total abdominal hysterectomy with bilateral salpingo oophorectomy and pelvic lymph node dissection procedure as ESS has high chances of recurrence and metastases. Peritoneal washings taken which showed no abnormal finding. Uterus, cervix, bilateral fallopian tubes, ovaries and bilateral pelvic lymph nodes were normal. No evidence of malignancy seen in the samples. Hence a final diagnosis of endometrial stromal nodule was made. We did not do markers of hormone receptors as final histopathological specimen was negative.

\section{DISCUSSION}

Endometrial stromal sarcoma is rare malignant tumour of mesenchymal origin. The WHO recognizes three categories of endometrial stromal tumours: Endometrial stromal nodule (ESN), low-grade endometrial stromal sarcomas (LGESS), and undifferentiated endometrial sarcoma (UES). ESN and LGESS presents mainly in premenopausal age group with mean age of 40-55 years. UES that is high grade ESS usually presents in postmenopausal age group. The common presenting symptoms are abnormal uterine bleeding, pelvic pain, pressure symptoms, and urinary abnormalities, the initial clinical impression is usually a leiomyoma. ${ }^{1}$

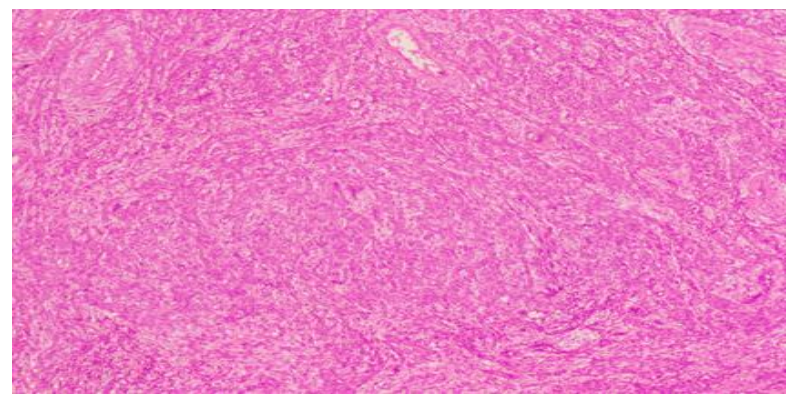

Figure 1: Photomicrograph of tumour comprising of proliferation of endometrial stromal cells in fascicles and around blood vessels, $(H$ and $E, 100 X$ magnification).

Diagnosis is made usually post operatively by histopathology and immunochemistry. Tumour shows wide range of behavior and can spread locally to vagina, fallopian tubes, ovaries, bladder and ureters. Distant metastases is also seen to heart and lungs. ${ }^{2,3}$ Prognosis depends upon stage of disease. FIGO staging of ESS is similar to uterine carcinoma. ESN and ESS are difficult to diagnose and even more difficult to differentiate on basis of curettage specimen, so hysterectomy specimen is must for differentiation and for further management. Myometrial and vascular invasion are the two main features that help us to differentiate ESS.

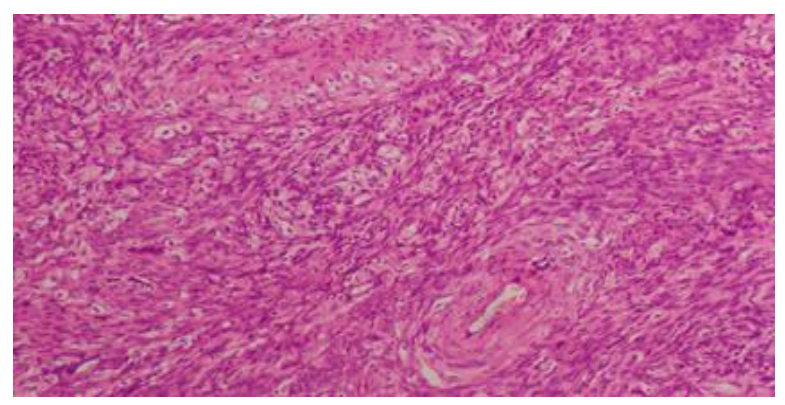

Figure 2: Photomicrograph of tumour cells with round to oval nucleus with finely granular dispersed chromatin and inconspicuous nucleoli, with few hemorrhagic areas (H and E, 400X magnification).

From ESN and the UES resembles the sarcomatous component of carcino sarcoma, hence extensive sampling of the tissues is required for confirmation of diagnosis. ${ }^{4}$ In contrast to ESS, ESN which is considered benign has smooth, expansile, non-infiltrating margins on histology whereas ESS has infiltrating irregular margins. Focal irregularities in the form of lobulated or finger like projections into the adjacent myometrium that are not $>3$ $\mathrm{mm}$ and are not exceeding three in number, however, may be seen in ESN. ${ }^{5}$ In low grade ESS, cords of tumor cells infiltrate between smooth muscles and lymphatics, hence extensive sampling of tumor margin for detection of myometrial involvement, vascular invasion and lymphatic invasion is required. Neoplastic stromal cells are monotonous in appearance with uniform shape and size (Figure 1), round to oval nuclei with fine chromatin and small nucleoli (Figure 2), and resemble to proliferative endometrium. ESS and leiomyoma are differentiated by immunochemistry with CD10 and smooth muscle actin and desmin (Figure 3), for surety of diagnosis.

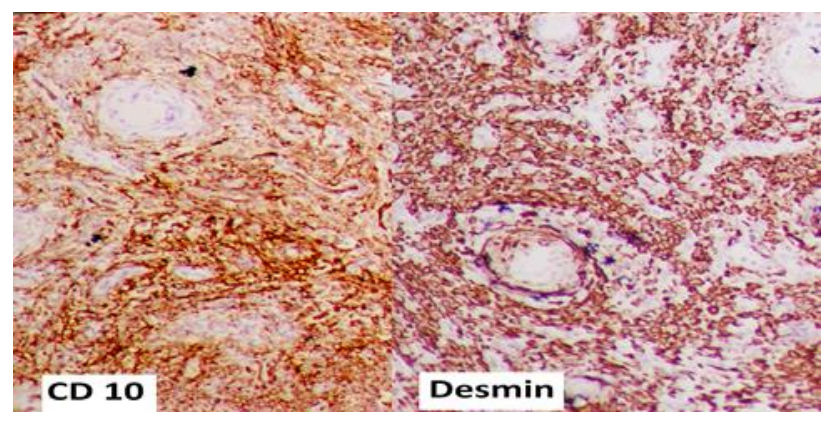

Figure 3: Photomicrograph of tumour cells positive for both CD10 and design on immunohistochemistry.

Management primarily involves surgery and extent of surgery depends upon stage of disease. Peritoneal washings are taken from pelvis and abdomen to see any 
spread in cavity. Total abdominal hysterectomy with bilateral salpingo -oophorectomy and pelvic and paraaortic lymph node dissection is surgery of choice. In hormone receptor positive cases, low grade ESS stage 34 , and in cases of recurrence medroxyprogesterone acetate, tamoxifen, GnRH analogues, aromatase inhibitor is suggested. ${ }^{6,7}$

\section{CONCLUSION}

Endometrial stromal sarcomas are rare entity, diagnosis is often made post operatively, and high index of suspicion, histology and immunochemistry aid in diagnosis. Management involves extensive surgery and postoperative hormonal therapy. Because of its rarity multi analysis from larger group of patients is required for diagnosis, prognosis and proper treatment.

\section{Funding: No funding sources}

Conflict of interest: None declared

Ethical approval: Not required

\section{REFERENCES}

1. Landreat V, Paillocher N, Catala L, Foucher F, Descamps P, Levêque J. Low Grade Endometrial Stromal Sarcoma of the uterus: Review of 10 cases. Anticancer Res. 2008;28:2869-74.
2. Matsuura Y, Yasungag K, Kuroki H, Inagaki H, Kashimura M. Low-grade endometrial stromal sarcoma recurring with multiple bone and lung metastases: report of a case. Gynecol Oncol. 2004;92:995-8.

3. Aubry MC, Myers JL, Colby TV, Leslie KO, Tazelaar HD. Endometrial Stromal Sarcoma Metastatic to the lung: A detailed analysis of 16 patients. Am J Surg Pathol. 2002;26:440-9.

4. Nicolas ML, Cathro HP, Kerr SE, Stelow EB. Cytomorphologic features of low-grade endometrial stromal sarcoma. AJR Am J ClinPathol. 2007;128:265-71.

5. Baker P, Oliva E. Endometrial stromal tumours of the uterus: A practical approach using conventional morphology and ancillary techniques. J Clin Pathol. 2007;60:235-43.

6. NCCN Clinical practice guidelines in oncology. Uterine neoplasms. 2009;2.

7. Linder T, Pink D, Kretzschmar A, Mrozek A, Patience PC, Reichardt P. Hormone treatment of endometrial stromal sarcomas: A possible indication for aromatase inhibitors. J Clin Oncol. 2005;23:16S9057.

Cite this article as: Baghotia $\mathrm{P}$, Madaan M, Pujani M, Soni N. Endometrial stromal nodule: a rare entity presenting as fibroid polyp. Int J Reprod Contracept Obstet Gynecol 2021;10:769-71. 